\title{
New Artistic-Iconological Interpretations in Ecourbarchitecture
}

\author{
Nikola Cekic \\ University of Niš, Niš, Serbia
}

\begin{abstract}
In this paper, the author focuses on the ecourbarchitectonic physical structures created after year 2000, whose artistic-esthetic value has an iconological character. An entirely new approach in formation of the facade and roof planes as well as of the forms of structures whose appearance resemble sculptural creations has been analyzed. The buildings from all over the world, with different functions contents, indicate a tendency of a different understanding of interpretation of physical structures and correlation with natural and artifact environment. Water surfaces and vegetative material contribute to an effective, cultural, majestic impression of engineering-technological philosophy of city building. The examples in the paper suggest the obvious need of radical changing of the way of thinking in the application of the design strategy in conceptualization of urban agglomerations, and essentially important, conceptually inspired metabolic of relationships among the spatial structures. The world entered new non-globalization trends of creation of the city memory, of the new iconically, symbolically strong, non-cliché, non-standard forms which define the contemporary cultural-artistic and historical identity of macro-ambient entities. This is a good and encouraging sign.

Keywords: iconological, ecourbarchitecture, archisculptural, interpretation, historical natural patterns, location conditions
\end{abstract}

\section{Introduction}

Powerful globalization tendencies in ecourbarchitecture caused universalizing of the images of environments, micro-ambient entities, and physical structures, and of their identity. Authenticity, distinctness, local colors, spirit, and historicity of places disappear at a dramatical rate, and artistic-formal and esthetic errors in space noticeably multiply. There reigns a chaos at an incredible scale, buildings are constructed according to the latest style, without measure and justification. The structures are not in a mutual dialogue, there is neither synthetic metabolics nor the beauty of volumes in exterior and interior space. The unjustified introduction of elements of other cultures to one's own brings about an artistic-spiritual devastation, unfortunate alteration of a location's character, unintelligible interpretations observed on the house facades which are not a contribution to the culture of the future. There is a small number of refined, sensitive creators, architects, designers, and thinkers who struggle to break free from the formal and structural monotony and to articulate new, fresh "youthful" ideas, to transform the architecture of spatial forms using a new geometrical-structural and material vocabulary. This paper is focused on the advent of the culture of the future and on a different spirit of the time, on a new artistic morphology in creation of ecourbarchitectonic works.

Nikola Cekic, Ph.D., Professor, Faculty of Civil Engineering and Architecture, University of Niš. 


\section{Impact of Contemporary Materials on Iconical-Ecourbarhitectonic Characteristics of Physical Structures}

Emergence of new artifact building materials, especially at the turn of this century, strongly affected the change of ideas in conceptualization of structural-esthetic and functional artistic characteristics of houses. The progressively prominent, inspiring forms, brought about complex, conceptually multi-layered, fluttery, elegant, more beautiful, and better designed volumes with archisculptural properties and with a fusion of natural materials from the environment. Using a different, conicoid geometry, wavy, warped surfaces, and interwoven modern material, can promote interesting volumes which are not structured on orthogonal, rigid engineering matrices, but on the logical natural patterns (snail, sea shells, honeycomb, skeletons etc.). They announce innovated structures are of powerful symbolical value, new artistic-iconological interpretations in ecourbarchitecture, a distinct morphology and bionics, new, and better artistic understanding of the world featuring a more civilized landscape.
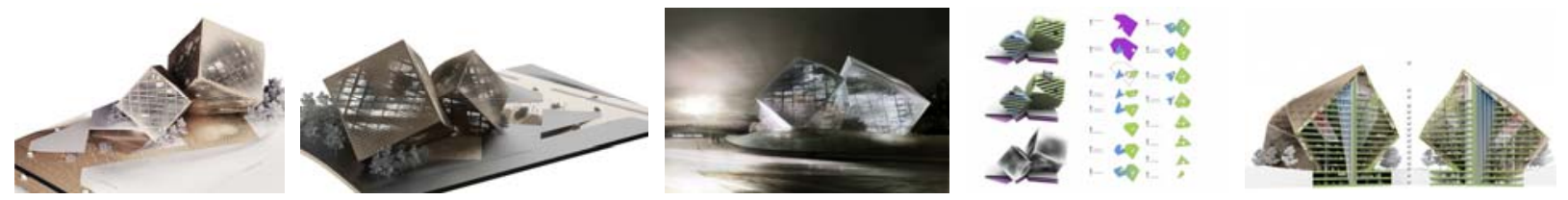

Figure 1. Administrative office headquarters of "S. Deer Corporate", HQ Nanjing, China.

Source: https://d2iweeeny6suwz.cloudfront.net/thumbnails-PRODUCTION/aa/36/aa36dc5c74db38be33517f7e21b49719.jpg; https://d2iweeeny6suwz.cloudfront.net/thumbnails-PRODUCTION/77/4b/774b2d2b36538f6b2a945a88255083d7.jpg; http://leatelierdulumiere.files.wordpress.com/2012/05/1337020790-sdeer-prechteck-00a-1000x650.jpg

The idea for design of the building, administrative office headquarters of "S. Deer Corporate", HQ Nanjing, featuring two rotated "embracing cubes", of different dimensions and with attractive inclined double-skinned facades originated from the Chinese designers ${ }^{1}$. The perforated-textile and glass surfaces provide a visual communication with the external environment; they also provide natural lighting of the interior. Solar panel surfaces make the building energy efficient and the vegetative park structure in a part of the building emphasizes the ecological relation to the environment, which contributes to a better micro-climate of the interior. It is intended to promote the world of fashion and affirm the living style of the corporation. The implementation of two cubes, whose expressive, dominant, and monumental configuration features an original, refined archisculptural expression with a simple, artistic-iconological interpretation.
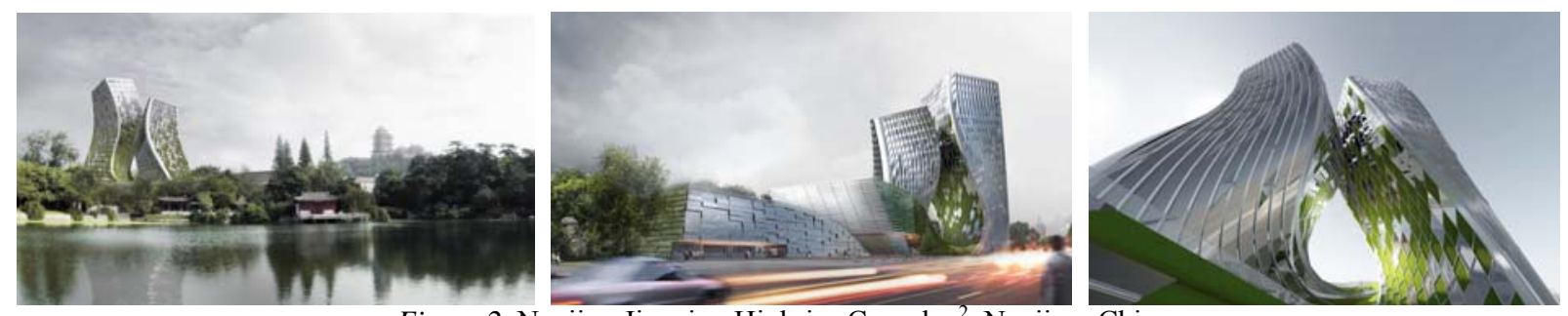

Figure 2. Nanjing Jianning Highrise Complex ${ }^{2}$, Nanjing, China.

Source: http://www.worlduc.com/blog2012.aspx?bid=3462215

1 Architekture: "Prechteck"; Location: Nanjing, China; Design team: Chris Precht, Fei Tang, Daniel Mayer; Client: S.deer/concept; Property surface area: $14,000 \mathrm{~m}^{2}$; Floor surface area: 28,500 m²; Height: $60 \mathrm{~m} \times 15$ floors.

2 Design: Nanjing Jianning Highrise Complex; Designed by W2Y2L; Design team: Xinyu Wan, Dingliang Yang, Keming Wang, Jialong Lai, Jie Li; Location: Nanjing, China. 
A similar logic is present in the ecourbarchitectonic and sculptural structure of Jianning Highrise Complex in Nanjing, China. There are also two craftily deformed volumes, two vertical, prismatic "embracing" form, joined with the vegetative materials and water surface in the immediate neighborhood, create and impressive ecourbarchitectonic, material, artistic-coloration synthesis. The concept of the appearance of the curved facade surfaces with vegetation blends in the total ambient articulation of the locality. The position of avant-garde, non-stereotypic architectonic structures is formally inspired by the concept of traditional Chinese gardens with hillocks, rocks, flowers, bridges, and water, spontaneously galvanizing the entire immediate surroundings. The green envelope promotes an attractive hybrid-contact between artifact and natural materials. The achieved artistic-interpretative quality can be perceived in the harmonious organization of vertical and horizontal forms, with a perfect understanding of the harmony of the existing fabric, in the coordinated interplay of architectonic masses and in the established spatial harmony. This is a model of how the environmental-cultural building balance ought to be revitalized and established, without any aggressive, too many times seen formalism.
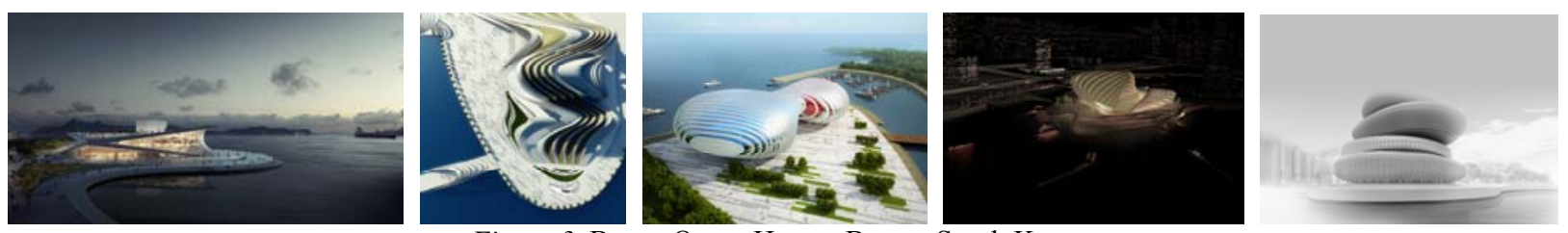

Figure 3. Busan Opera House, Busan, South Korea.

Source: http://www.bustler.net/index.php/article/snohettas_winning_design_for_the_new_busan_opera_house/;

http://www.arch2o.com/wp-content/uploads/012/10/Arch2O-Busan-Opera-House-03.jpg;

https://acdn.architizer.com/thumbnails-PRODUCTION/de/11/de115c299ec36f61e694f988f21e61bd.jpg;

http://www.worldofarchi.com/2012/06/busan-opera-house-by-ooda.html;

http://www.bustler.net/index.php/article/busan_opera_house_proposal_by_praud/

The projects for the conceptual town planning and architectonic design of the Busan Opera House in South Korea, featured outstanding propositions with numerous innovative-artistic visions. The competition indicated that he in the world of ecourbarchitectonic thought, there has been a significant conceptual change without polygonal, sharp-angled, or rectilinear volumes. Archisculptural quality, with soft contours of volumes and biomorphic elements in the forms was present in most of the designs. Location conditions, with a vast sea surface and mountains in the background affected the process of finding the most adequate design, and affected the inter-relations with the natural materials in the environment. The presented projects had high functional clarity, harmonized relations to the physical structures in the background; they had and iconically ripe, clear artistic structure. The winner was "Snøhetta", Norwegian team with the concept of so-called "unpacked box". The proposition was conceived with still music and exquisite acoustics in the central hall. The opera is an elite place with an important identity, influencing the further development of new cultural-city building forms of the city of Busan.

\footnotetext{
3 See http://snohetta.com/project/12-busan-opera-house. Architecture: Environment and Interior 2012; Client: "Busan Metropolitan City Government”; Typology: performance space in construction; Status: first prize at the international competition for development design and architecture; Surface area: $48.000 \mathrm{~m}^{2}$. Busan, South Korea; Local partner: Ilshin Architects.
} 

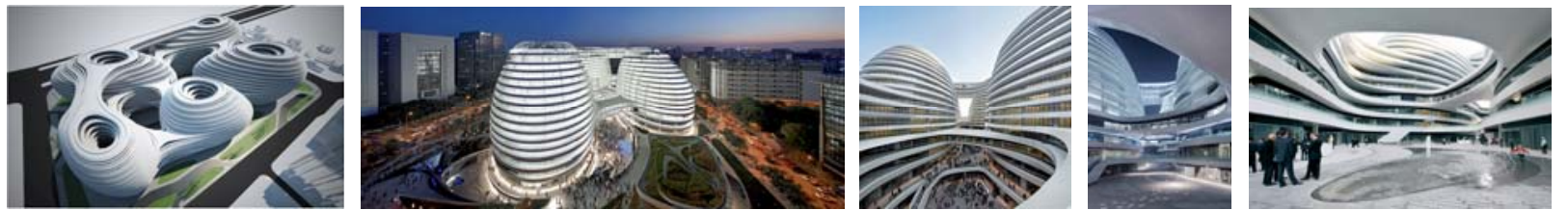

Figure 4. Multifunctional structure-Chaoyangmen Beijing SOHO III

Source: http://www.2-french.com/a-portrait-of-zaha-hadid/?lang=en\#;

http://2.bp.blogspot.com/-iKLvaWs8HIs/UJtFZx_gOeI/AAAAAAAAAHc/iD5k6fTWQEw/s1600/RjnNU.jpg;

http://thearchandthedome.wordpress.com/2013/07/07/galaxy-soho/

In the central zone of Beijing-Chaoyangmen SOHO III, on an island, Zaha Hadid designed a building with $334,000 \mathrm{~m}^{2}$ of useful surface area, having a multifunctional character. It is the largest commercial project in the east part of the city. The concept of a business structure is created with five Chinese courtyards, traditionally placed in the center of the volumes and with two atriums. Design and understanding of spatial forms-ecourbarchitectonic forms is quite dissimilar from the neighboring buildings. The inspiration for prominent, soft, curvilinear geometry originates from the natural forms. There are no polygonal, sharp-angled volumes, so that the facade appearances have a sculptural narrative. The buildings are mutually continuously connected. There is an excellent physical communication, good access to the building from all sides and the visual openness to surrounding city area. Contemporary and simple forms are a harbinger of a new interpretative urban design and a building strategy for the 21 st century.
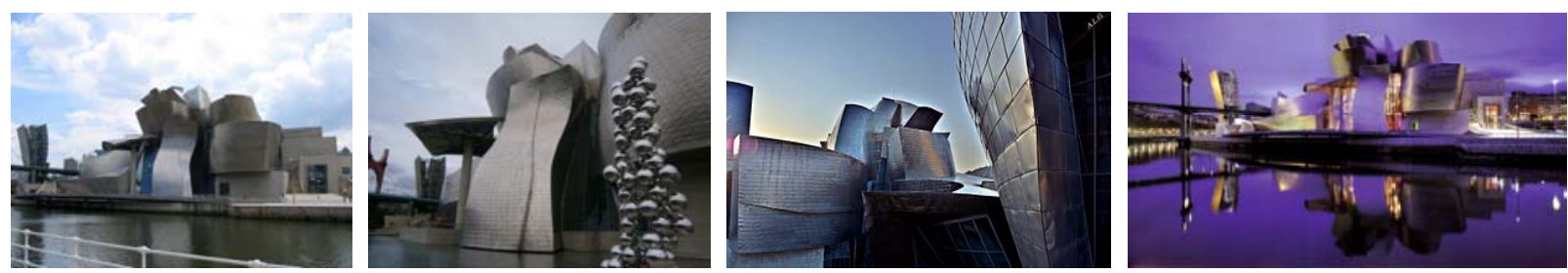

Figure 5. "Guggenheim Museum" in Bilbao, Museum of modern and contemporary art.

Source: http://www.archinoah.com/files/architekturfotografie/foto577.jpg

After four years of building, in 1997, on 19th of October, a new, architectonically fascinating "Guggenheim Museum" in Bilbao, Spain was opened. Philip Johnson, the famous architect, said that it was the greatest artistic-building and esthetic achievement of our times. The Canadian-American architect Frank Gehry very inventively designed a first-class, attractive building intended for cultural activities, with neo-orthodox materials and with artfully deformed façade surfaces made of titanium sheets. The new way thinking in formation of buildings turned a new page of ecourbarchitecture history. It won the first place at the international town planning and architectonic competition for conceptual design of the building. It turned a new page of history in ecourbarchitecture. It moved the temporal frontiers in understanding of urban design, and established a new spirit of interpretation of physical structures in space. The location in the Bay of Biscay, with a lot of water in the Nervion River, in the contact zone, and the background of the old city were a special designing challenge, for which the author's sensitivity for the urban environment and creation of a new, refined identity of the place had a priority. It was not an artistic experiment, even though the building has a modern expression and a powerful, balanced, and archisculptural character, with grouped parts in entirely new non-standard relations. This iconical and significant structure reveals the future inexorable changes in the art of building-shaping, in the orientation and tendency of expanding the conceptual and designing boundaries. In general, it expands our intellectual notions of a city. 

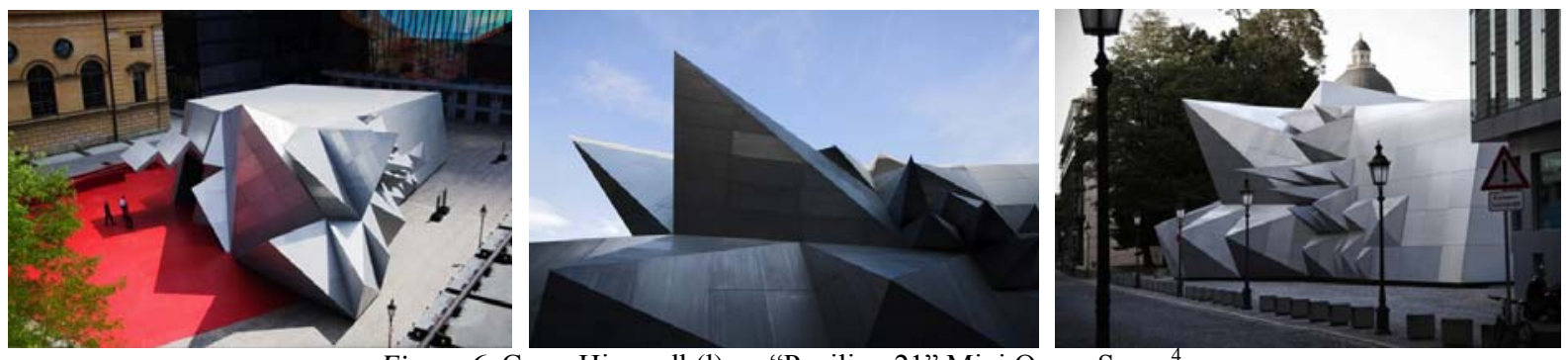

Figure 6. Coop-Himmelb(1)au: "Pavilion 21" Mini Opera Space".

Source: http://beautifuldecay.com/2010/07/06/form-function-awesome-architecture/

Pavilion 21 "Mini Opera Space", was planned with a capacity of 300 seats (700 standing spaces) for experimental performances in the Bavarian state opera. It was planned to be assembled and disassembled with good acoustics and recognizable, accentuated design in architecture. The decisive condition in the design specifications, "to provide good acoustics in a small building mass" was not easy to meet, at all. The sound frequency analyses in the interior resulted in design of pyramidal, pointy and irregular parts of the structure, through a parametrical design method and usage of state-of-the-art building materials; the intention was to eliminate the street noise, create a good, attractive facade appearance and provide a quality protective barrier between the square and the street. The interior of the structure, wall, and ceiling surfaces are lined with perforated sound-absorbing panels. In the esthetic-artistic sense, the designers exhibited high sensitivity for boldly generated "animated" architecture; none would call it exclusive, sculptural, complex, originating from musical scores. Ecourbarchitectonic composition of the physical structure of the pavilion is represented in a new way, on an island location, which does not have an organic-metabolic or cultural-historical dialogue with the surrounding building. Much as it appeared contrasting and intruding, this fascinatingly iconical and scenic architecture seems inspirational and motivational for promotion of city-building, artistic, picturesque spatial interpretations and changes of the cityscape
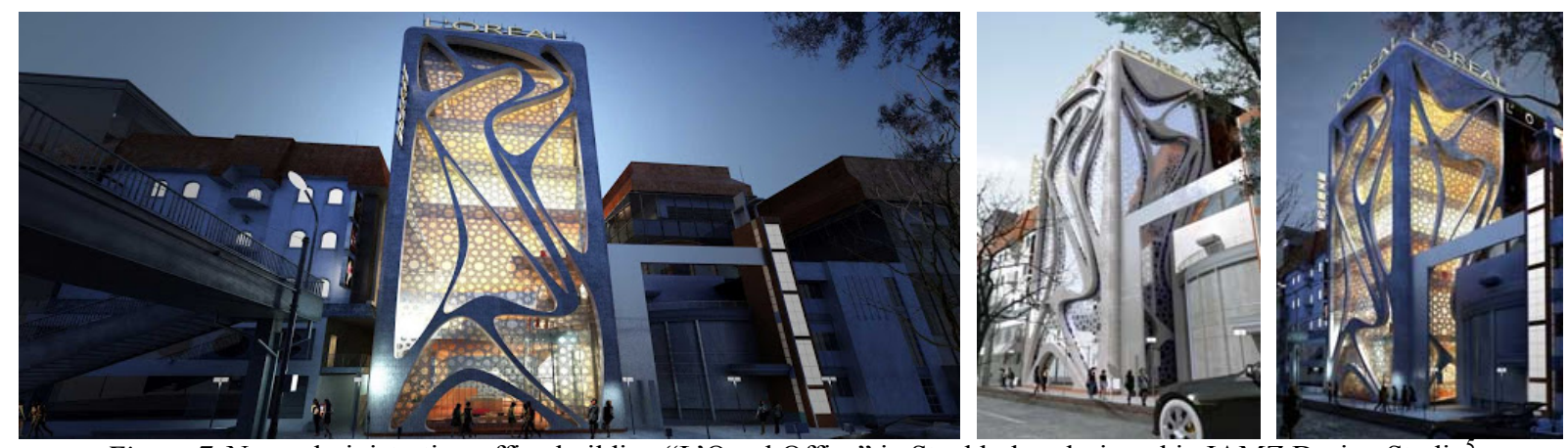

Figure 7. New administrative-office building "L'Oreal Office" in Stockholm, designed in IAMZ Design Studio ${ }^{5}$

Source: http://www.aasarchitecture.com/2013/05/Oreal-headquarters-IAMZ-Design-Studio.html

\footnotetext{
${ }^{4}$ Coop-Himmelb(1)au, Wolf D. Prix/W. Dreibholz \& Partner ZT GmbH; Main design: Wolf D. Prix; Design partner: Paul Kath; Architecture designer: Volker Kilian; Architecture designer: Sophie-Charlotte Grell; Design team: Daniel Bolojan, Wendy W Fok, Martin Jelinek, Daniela Kröhnert, Valerie Messini, Judith Mussel, Martin Neumann, Renate Weissenböck; "Coop-Himmelb(1)au" (Established: 1968) is a designing-architectonic firm with the headquarters in Vienna and branches in Los Angeles, USA and Guadalajara, Mexico.

${ }^{5}$ Development section and investments: "L'Oreal products company"; Surface: $100 \mathrm{~m}^{2} \times 6$ floors; Designer: IAMZ Design Studio. Web page: http://www.iamz.org; Arhcitect: Ahmed Elseyofi. Website: http://www.seyofi.info; Techncal supervizor: Dilman Majid. Identity, architecture, and meditation. L'Oreal: "Our design is a part of the identity of this zone".
} 
The designers of IAMZ Design Studio, provided a conceptual design for an office building of the worldwide known cosmetics corporation "L'Oreal", Office in Stockholm. Not only are the front façade, but also the structural and artistic-designing, material composition obviously different, in the artistic-interpretative and cultural terms from the adjacent buildings. The composition of the new creation contains two facades: The first one, from the street side has a strong, significant formal hydro-fluid expression with perforations that should create an illusion of freshness, in the visual communication with the users. The second façade is made of glass, with discreetly applied lacy and honeycomb mesh elements. In the quest for an architectonic symbolism of the place identity, a unique artistic concept was implemented, with organic, unconventional, and geometrical forms that leave impressions of fluid movements, spirit of naturalness and beauty of the company's products. The impression is there, in daylight and at nighttime.
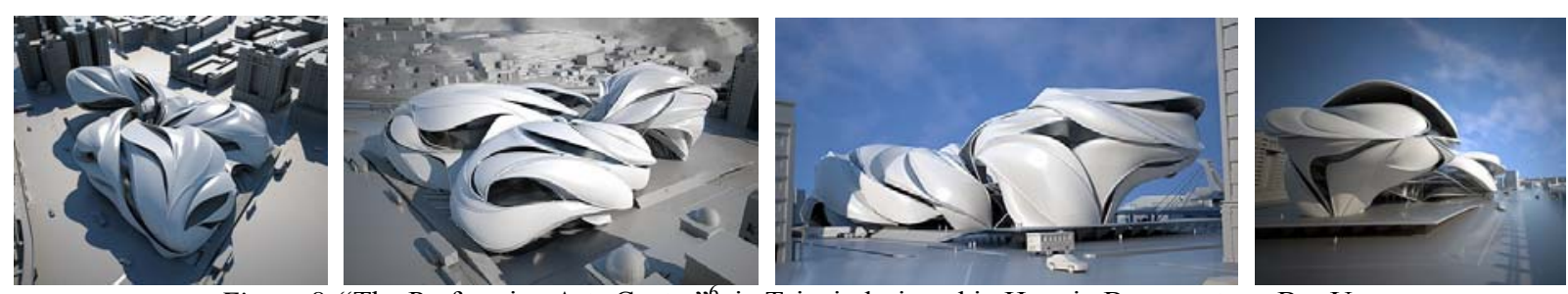

Figure 8. "The Performing Arts Center" in Taipei, designed in Herwig Baumgartner, B + U.

Source: http://holst.com.ua/blog/2010/07/12/taipei/\#more-3033; http://www.sciarc.edu/news_archive.php?id=1415

Ecourbarchitectonic concept for the conceptual design of The Performing Arts Center in Taipei is a landmark entity which establishes a new way of building formation. Building shape and morphology were designed based on the analysis of sound wave effects transformed into three dimensions of vectors. The vectors determined the formal and structural framework for design of exteriors and facades. The building was materialized using metal and glazed contemporary materials which reveal the powerfully transformed, warped, and regularly deformed sculptural surfaces in different positions. There are no angled, polygonal nor flat vertical or horizontal panel surfaces, like those in the immediate surroundings. The architect Zaha Hadid, whose architectonic works are similarly designed, said, "The world of architecture is not any longer based on the rectangular, rigid layouts..." The structure is dominated by fluid lines, wavy surfaces and gaps through which daylight is introduced into the interior. The revolutionary era of new forms in ecourbarchitecture-of biomorphic character has begun. It seems that a solution for leaving the realm of rectangular problems and same looking window facades has been found. The building expresses an abundance of various artistic and functional planning-city-building influences with which the city enters a different heteronymous order of physical structures in space.

\footnotetext{
${ }^{6}$ Architecture: B + U, LLP; 834 S. Brodway 5020 Los Angeles, CA 90014. Herwig Baumgartner, principal: Scott Uriu; Main location: Taipei, Taiwan. Client: Taipei City Government, Department for cultural affairs; Program: Center for artistic performances, opera house, entertainment center and polyvalent theater; Size: $40,000 \mathrm{~m}^{2}$. Competition project, construction completion date: 2008; Material: steel, metal, and glass; Design team: Paul Macherey, Justin Oh; Phillip Ramirez, Art Zargaryan; Daniel Saltee, Yaohua Wang; Structural engineering: “ARUP” company; Mechanical engineering: “ARUP” company. Associaton of architects: S. C. S \& Associates.
} 

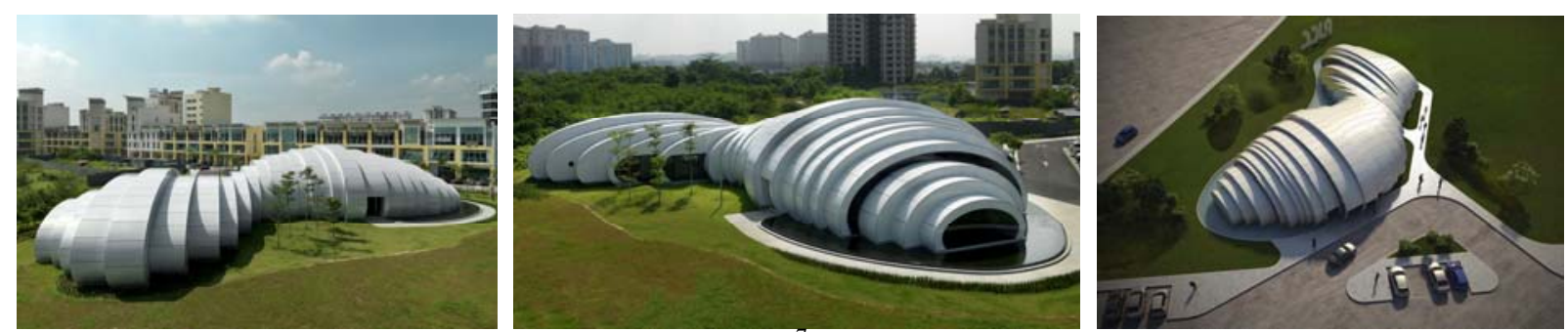

Figure 9. "POD" Exhibition pavilion" in Jaya, Kuala Lumpur, Malaysia.

Source: http://www.artribune.com/wp-content/uploads/2011/07/Studio-Nicoletti-Associati-The-Pod-Kuala-Lumpur-Malesia-2.jpg; http://www.artribune.com/wp-content/uploads/2011/07/Studio-Nicoletti-Associati-The-Pod-Kuala-Lumpur-Malesia-1.jpg; http://4.bp.blogspot.com/-Nz_QzuUt7Zs/UfIOckwlWyI/AAAAAAAAm_U/yjouzV3xb4A/s1600/THE+POD+BY+STUDIO+NIC OLETTI+ASSOCIATI+WITH+HIJJAS+KASTURI+ASSOCIATES+SDN+02.jpg

In the territory of Petaling Jaya, in Kuala Lumpur, Malaysia, a new urban center with multiple attractive architectonic structures is being constructed. "POD" exhibition pavilion is an iconical part of the complex. It reflects the spiritual power of the place and the style of environmental building, through its employment of the state-of-the-art materials. The idea to use a playful, biomorphic, segmental, elliptic structure, extending horizontally in a natural environment is accentuated by the new language of "cladding" the façade surface using material which during the day changes its coloration depending on the position of sun and intensity of sunlight. Dynamical, spherical forms in the composition generate a myth of creation of a different, futuristic formation of physical- "urbanomorphic" structures of the city, and a historical pattern of its uniqueness. This design changes the concept of sustainability and development of the region, material-cultural and spiritual essence of the city, and construction of the image of its expressiveness. The idea and intent to venture out into a world new artistic-formal-esthetic coordinates outside the acquired city-building - designing experience, and to propose a representative constructive landmark, imaginative iconical, spatial, and improved pattern in the system of new urban implications.
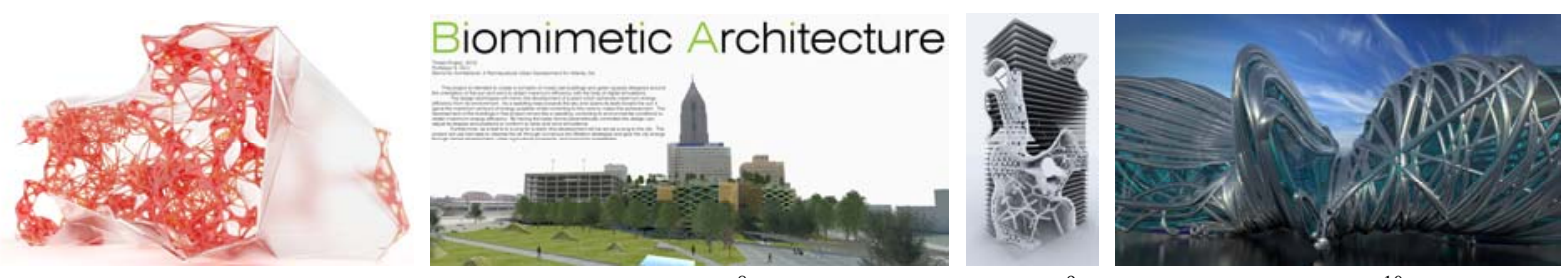

Figure 10. Design: Morphogenetic structuralism ${ }^{8}$, Biomimetic architecture $^{9}$, Parametric architecture $^{10}$

Source: https://lh6.googleusercontent.com/-6nPOteR30I8/UGnCuVz3C_I/AAAAAAAAAII/Y1ivFRaSrWc/w800-h800/20b.jpg; http://jshannonstudio.com/?page_id=163;

http://www.pinterest.com/pin/520306563169442760/;

http://www.cgarchitect.com/content/portfolioitems/2012/02/46177/parametric_architecture_large.jpg

Very rapid advance of computer technologies in designing of structures, especially in creation of new structural and material technical solutions, facilitated large changes, synthetic in character in ecourbarchitecture. Various multidisciplinary scientific methodologies are present in generation of new morphogenetical physical

\footnotetext{
${ }^{7}$ Design: Manfredi Nicoletti, Studio Nicoletti Associati and Hijjas Kasturi, Hijjas Kasturi Associates Sdn; Development: "MKH Group", Malaysia; Construction: Bina Jurati Sdn Bhd; Size: $800 \mathrm{~m}^{2}$. See https://plus.google.com/104962641191329615146/ about?gl=rs\&hl=sr

${ }^{8}$ See http://www.pinterest.com/pin/397513104579491407/

9 See www.biomimetic-architecture.com

${ }_{10} \mathrm{See}$ http://www.huffingtonpost.com/adel-zakout/top-10-buildings-parametr_b_838268.html
} 
structures: mathematical—calculation of algorithms, neurophysiological, biological, social, etc. All the approaches in designing of non-globalist forms, have a goal to redirect the chaotic courses in the artistic-esthetic and city-building development. To transpose the complex structural forms from the realms of flora and fauna into an engineering code, to arrest them in morphodynamic evolution and reorganize them in accordance with new discoveries and materials. Model testing based on post-structuralism opens new vistas, expands the frontiers striving for creation of more esthetic places, houses and cities. Thus, biomimetic and contemporary philosophy of ecourbarchitecture seeks the connections with the nature, in a sustainability in which nature will not be a mere replica. By mimicking the natural forms, analyzing their models, compositions and processes, it is possible to obtain a more inspiriting design of structures in the environment in order to improve the current status of artifact micro-ambient entities. Using computers, we can simulate future concepts of cities and houses, create sublime formal presentations and decode new spatial-iconical values, create functional-artistic, contemporary and futuristic interpretations of horizontal and vertical volumes. By mapping data, mathematically, we can parametrically adjust architectonic forms to the terrain contours, and produce new designing-visual, synthetic presentations. Parametric design is a new, powerful, impressive planning tool, with a multitude of organic variables for designers, at the turn of this century.

\section{Conclusion}

Ten presented examples from the world of ecourbarchitecture indicate a tendency of creation of urban-artistic-iconological structures, esthetic and sculptural in terms of their narration, from which we can infer new imaginative and functional compositions of expanding cities. The ideas of prefabricated, "ready-made" structures created on strictly defined, modular orthogonal networks have been abandoned. There is no defined utilitarianism or rigid engineering. The impressive symbolical value of the structures has dominant place. Geometry of these houses is coordinated with the natural environment and artifacts in the immediate environment. The accent is on design of physical structures, with drastically deformed façade envelopes, imitating the natural forms, on new structural technical solutions wherein digital panels become a modern tool and material in city building where ecourbarchitectonic creations live 24 hours a day. We are in a new artistic-cultural, creative revolution which brings about spatial-iconological, dynamical-contrasting images of the city and new artistic-formal spirituality. By all means, it brings about a fresher city-building memory of ambient entities and different strategy of style in house formation based on contemporary materials and structures. We are dealing with an ecourbarchitectonic philosophy in the quest for morphogenetic, biomimetic and parametric forms and their organic interpolation-coordinating with the existing environment. We are looking for more effective, more human-scaled functional volumes and interpretations of houses. We focus our attention on the artistic-iconical tools, on formation of more functional physical structures in a complex and contradicting space, which lacks more sensitive alterations. We seek to find answers through additions, context and integration of ecourbarchitectonic heteronymous structures, to implement a wiser planning activity with new spiritual-artistic philosophy to create human-suited cites, of an epic power and wide contemporaneity. The cities we need nowadays.

\section{References}

Allen, E., \& Zalewski, W. (2009). Form and forces: Designing efficient, expressive structures (1st ed.). New York, NY: John Wiley and Sons. 
Boswell, K. (2013). Exterior building enclosures: Design process and composition for innovative facades (1st ed.). New York, NY: John Wiley and Sons.

Bradbury, D., \& Powers, R. (2009). The iconic house: Architectural masterworks since 1900. London: Thames \& Hudson.

Bruderlin, M. (2004). Archi-sculpture: Dialogues between architecture and sculpture from the 18th century to the present day. Berlin, Stuttgart: Hatje Cantz Verlag.

Gupta, R. S. (2010). Principles of structural design: Wood, steel, and concrete (1st ed.). Boca Raton, Florida: CRC Press. Jabi, W., Johnson, B., \& Woodbury, R. (2013). Parametric design for architecture. London: Laurence King Publishing.

Jenks, M., \& Dempsey, N. (2005). Future forms and design for sustainable cities (1st ed.). Thames, United Kingdom: Taylor \& Francis.

Jodidio, P. (2013). Architecture now! (Vol. 9). Publisher: Taschen.

Mallgrave, H. F., \& Contandriopoulos, C. (2008). Architectural theory: An Anthology from 1871 to 2005 (1st ed., Vol. 2) Hoboken, New Jersey: Wiley-Blackwell.

Weston, R. (2010). Key buildings of the 20th century: Plans, sections and elevations (Key Architecture Series, 2nd Edition). New York, NY: W. W. Norton \& Company. 